\title{
Down-regulation of the cardiac sarcoplasmic reticulum ryanodine channel in severely food-restricted rats
}

V.A. Vizotto ${ }^{1}$, R.F. Carvalho ${ }^{2}$,
M.M. Sugizaki ${ }^{1}$, A.P. Lima ${ }^{1}$,
F.F. Aragon ${ }^{3}$ C.R. Padovani ${ }^{3}$,
A.V.B. Castro ${ }^{1}$,
M. Dal Pai-Silva ${ }^{2}$,
C.R. Nogueira ${ }^{1}$
and A.C. Cicogna ${ }^{1}$

\author{
'Departamento de Clínica Médica, Faculdade de Medicina de Botucatu, \\ ${ }^{2}$ Departamento de Morfologia, ${ }^{3}$ Departamento de Bioestatística, \\ Instituto de Biociências de Botucatu, Universidade Estadual Paulista \\ "Júlio Mesquista Filho", Botucatu, SP, Brasil
}

\section{Correspondence \\ A.C. Cicogna \\ Departamento de Clínica Médica Faculdade de Medicina de Botucatu UNESP \\ Rubião Júnior, s/n \\ 18618-000 Botucatu, SP \\ Brasil \\ Fax: +55-14-3882-2238 \\ E-mail: cicogna@fmb.unesp.br \\ Research supported by FAPESP (No. 02/12314-5), CNPq (No. \\ 302502/2004-1), and Faculty of Medicine, UNESP, Botucatu, SP, Brazil.}

Received May 9, 2006 Accepted October 24, 2006

\begin{abstract}
We have shown that myocardial dysfunction induced by food restriction is related to calcium handling. Although cardiac function is depressed in food-restricted animals, there is limited information about the molecular mechanisms that lead to this abnormality. The present study evaluated the effects of food restriction on calcium cycling, focusing on sarcoplasmic $\mathrm{Ca}^{2+}$-ATPase (SERCA2), phospholamban (PLB), and ryanodine channel (RYR2) mRNA expressions in rat myocardium. Male Wistar-Kyoto rats, 60 days old, were submitted to ad libitum feeding (control rats) or 50\% diet restriction for 90 days. The levels of left ventricle SERCA2, PLB, and RYR2 were measured using semi-quantitative RT-PCR. Body and ventricular weights were reduced in 50\% food-restricted animals. RYR2 mRNA was significantly decreased in the left ventricle of the foodrestricted group (control $=5.92 \pm 0.48 v s$ food-restricted group $=4.84$ $\pm 0.33, \mathrm{P}<0.01)$. The levels of SERCA2 and PLB mRNA were similar between groups (control $=8.38 \pm 0.44 v$ s food-restricted group $=7.96$ \pm 0.45 , and control $=1.52 \pm 0.06 v s$ food-restricted group $=1.53 \pm$ 0.10 , respectively). Down-regulation of RYR2 mRNA expressions suggests that chronic food restriction promotes abnormalities in sarcoplasmic reticulum $\mathrm{Ca}^{2+}$ release.
\end{abstract}

Food restriction induces beneficial health effects such as increased longevity and retards or prevents a broad spectrum of agerelated pathophysiological changes such as loss of skeletal muscle mass, diabetes mellitus, hypertension, and cancer (1-3). Recent research from our laboratory has shown that $50 \%$ food restriction promotes left ventricular dysfunction and increases contraction and
Key words

- Food restriction

- SERCA2

- Ryanodine channel

- Phospholamban

- mRNA relaxation times in isolated papillary muscle of both young Wistar-Kyoto normotensive and spontaneously hypertensive rats (4-7). Sugizaki et al. (7) observed that myocardial dysfunction in food-restricted rats is related to calcium handling. However, these investigators were unable to identify calcium handling site abnormalities.

Few studies have analyzed the molecular 
mechanisms related to myocardial $\mathrm{Ca}^{2+}$ cycling in the heart of food-restricted animals $(8,9)$. Intracellular calcium handling is regulated by the $\mathrm{Na}^{+} / \mathrm{Ca}^{2+}$ exchanger, L-type channel, sarcoplasmic reticulum (SR), ryanodine channel (RYR2), SR $\mathrm{Ca}^{2+}$-ATPase pump (SERCA2), phospholamban (PLB), and myofilament $\mathrm{Ca}^{2+}$ affinity (10). Thus, any alteration in the expression of $\mathrm{Ca}^{2+}$ related genes could lead to abnormal $\mathrm{Ca}^{2+}$ homeostasis and hence contractile dysfunction in cardiac tissue from food-restricted rats. Accordingly, O'Brien et al. (8) evaluated rats fed a low-protein-calorie diet to reduce their body weight by approximately $25 \%$ in 7 days, and concluded that hypocaloric feeding produces a compensatory, reversible, and asymmetric down-regulation of calcium cycling, with RYR2 activity being preferentially affected. Rupp et al. (9) analyzed the myocardium of rats submitted to 5 weeks of food restriction and showed a reduction in $\mathrm{SR} \mathrm{Ca}^{2+}$ uptake activity. Therefore, we hypothesized that RYR2, SERCA2 and PLB were responsible for the myocardial dysfunction observed in our previous studies $(6,7)$. The aim of the present study was to evaluate SERCA2, PLB and RYR2 mRNA in rats submitted to long-term severe food restriction.

Sixty-day-old male Wistar-Kyoto rats (WKY) were fed a control (CT, $\mathrm{N}=10$ ) or food-restricted diet (FR, $\mathrm{N}=10)$. The $\mathrm{CT}$ group was fed Purina rat chow $(3.76 \%$ fat, $20.96 \%$ protein, $52.28 \%$ carbohydrate, $9.60 \%$ fiber, and $13.40 \%$ humidity) and water ad libitum. The FR group received 50\% of the amount of food consumed by CT. Food consumption by $\mathrm{CT}$ animals was measured daily and used to calculate the food amount given to the FR group. Rats were maintained on this dietary regimen for 90 days. Although the FR group received 50\% the amount of food consumed by control rats, the Purina rat chow (www.agribrands. com.br) ingested by the FR group contained sufficient amounts of proteins, vitamins, and minerals for rat maintenance according to the Nutrient Requirements of Laboratory Animals (11). Rats were housed in individual cages in an environmentally controlled room with a temperature of $23 \pm 3^{\circ} \mathrm{C}$ and a 12-h light:dark cycle. Initial and final body weight (FBW), left (LVW) and right ventricular weight (RVW) were measured, and LVW/FBW and RVW/FBW ratios were calculated.

All experiments and procedures were performed in agreement with the Guide for the Care and Use of Laboratory Animals published by the U.S. National Institutes of Health and were approved by the Ethics Committee of Botucatu Medical School, UNESP, Botucatu, SP, Brazil.

Total RNA was extract from rat left ventricle with TRIzol reagent (Invitrogen, Life Technologies, São Paulo, SP, Brazil), which is based on the guanidine thiocyanate method. Frozen muscles were homogenized mechanically on ice in $1 \mathrm{~mL}$ of ice-cold TRIzol reagent. Total RNA was solubilized in RNase-free $\mathrm{H}_{2} \mathrm{O}$ incubated with DNase I (Invitrogen, Life Technologies) to remove any DNA present in the sample and quantified by measuring the absorbance at $260 \mathrm{~nm}$. RNA purity was ensured by obtaining a spectrophotometer (GeneQuant ${ }^{\mathrm{TM}}$ RNA/ DNA Calculator, Amersham Pharmacia Biotech, Cambridge, England) at 260- to280-nm absorbance ratio of $\sim 2.0$. Two micrograms of RNA was reverse transcribed with random hexamer primers and Superscript II RT in a total volume of $21 \mu \mathrm{L}$, according to standard methods (Invitrogen, Life Technologies). Control No RT reactions were carried out in which the RT enzyme was omitted. The control No RT reactions were PCR amplified to ensure that DNA did not contaminate RNA. One microliter of cDNA was then amplified using 1 $\mu \mathrm{M}$ of each primer, 1X PCR buffer minus $\mathrm{Mg}, 5 \mathrm{mM} \mathrm{MgCl} 2,1 \mathrm{mM}$ deoxyribonucleotide triphosphates, and 2 units of Platinum ${ }^{\circledR}$ Taq DNA Polymerase in a final volume of 
$25 \mu \mathrm{L}$. Primer pairs for RYR2, SERCA2a and PLB primer sequences were: PLB: sense 5'-TACCTTACTCGCTCGGCTATC-3'; antisense 5'-CAGAAGCATCACAATGA TGCAG-3'; SERCA2: sense 5'-ATGAGATC ACAGCTATGACTGGTG-3'; antisense 5'GCATTGCACATCTCTATGGTGACTAG3'; RYR2: sense 5'-GAATCAGTGAGTTAC TGGGCATGG-3'; antisense 5'-TTGGTCTC TGAGTTCTCCAAAAGC-3'; cyclophylin: sense 5'-ACGCCGCTGTCTCTTTTC-3'; antisense 5'-TGCCTTCTTTCACCTTCC-3' as proposed by Mirit et al. (12) and Coussin et al. (13). Preliminary experiments were conducted with each gene to determine the number of PCR cycles that represented the linear range of amplification. The cDNA from each muscle for both the CT and FR groups was amplified simultaneously using aliquots from the same PCR mixture. After PCR amplification, $10 \mu \mathrm{L}$ of each reaction was electrophoresed on $1.0 \%$ agarose gels stained with ethidium bromide. The images were captured and the bands corresponding to each gene were quantified by densitometry (UVP Laboratory Products - UV/White Darkroom, Upland, CA, USA) as integrated optical density by Labworks ${ }^{\mathrm{TM}}$ Analysis Software 3.0 (Upland, CA, USA). The PCR products were run in duplicate on different gels for each gene, and the results were averaged. The size (the number of base pairs) of each band corresponds to the size of processed mRNA. The target genes were normalized to the housekeeping gene cyclophilin (14).

Data are reported as means \pm SD. Data were compared between groups by the Student unpaired $t$-test. The level of significance was set at $\mathrm{P}<0.05$.

Table 1 shows the influence of 90 days of $50 \%$ food restriction on body and cardiac chamber weight. Food restriction significantly decreased body and ventricular weights, with similar magnitudes of the body and ventricular weight losses. Thus, LVW/ FBW and RVW/FBW ratios were similar for both groups.
Figure 1 shows the determination of myocardial SERCA2, PLB and RYR2 mRNA gene expression. The levels of SERCA2 and PLB mRNA in myocardium were similar for the two groups $(\mathrm{CT}=8.38 \pm 0.44$ vs $\mathrm{FR}=$ $7.96 \pm 0.45$, and $\mathrm{CT}=1.52 \pm 0.06$ vs $\mathrm{FR}=$ $1.53 \pm 0.10$, respectively). However, left ventricular RYR2 mRNA was significantly decreased in the FR group $(\mathrm{CT}=5.92 \pm 0.48$ vs $\mathrm{FR}=4.84 \pm 0.33 ; \mathrm{P}<0.01)$.

We have already established that food

Table 1. Food consumption and general characteristics of the rats used in the present study.

\begin{tabular}{lcc}
\hline & Control & Food-restricted \\
\hline $\begin{array}{l}\text { Food consumption } \\
\text { (g/day) }\end{array}$ & $22 \pm 2$ & $11 \pm 1$ \\
IBW (g) & $276 \pm 16$ & $280 \pm 20$ \\
FBW (g) & $464 \pm 39$ & $250 \pm 10^{*}$ \\
LVW (g) & $0.83 \pm 0.06$ & $0.46 \pm 0.02^{*}$ \\
RVW (g) & $0.26 \pm 0.04$ & $0.14 \pm 0.07^{*}$ \\
LVW/FBW (mg/g) & $1.80 \pm 0.06$ & $1.84 \pm 0.08$ \\
RVW/FBW (mg/g) & $0.55 \pm 0.05$ & $0.55 \pm 0.04$
\end{tabular}

Data are reported as means \pm SD for 10 rats in each group. IBW = initial body weight; FBW = final body weight; LVW = left ventricle weight; RVW = right ventricle weight.

${ }^{*} \mathrm{P}<0.001$ (Student $t$-test for unpaired data).

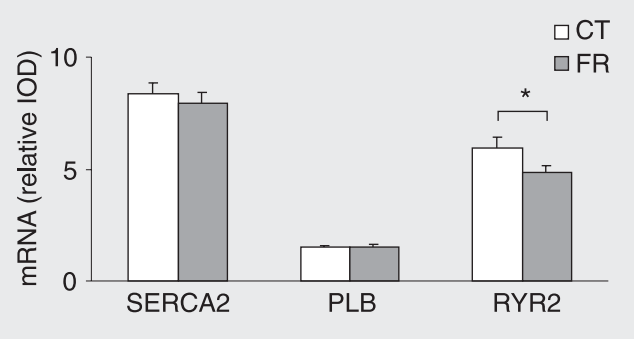

Figure 1. Semiquantitative RT-PCR analyses of myocardial sarcoplasmic reticulum $\mathrm{Ca}^{2+}$-ATPase (SERCA2), phospholamban (PLB), and ryanodine channel (RYR2) in control (CT) and food-restricted (FR) rats. The expressions of genes were normalized to the cyclophilin signal from the same RT product. Experiments were run in duplicate on different gels for each gene, and the results were averaged. PCR products were visualized with ethidium bromide staining. Quantitation of the PCR signal was obtained by densitometric analysis of the product as integrated optical density (IOD). Normalized data are reported as means \pm SD for 10 rats per group, ${ }^{*} \mathrm{P}<0.01$ (Student $t$-test for unpaired data). 
restriction impairs the mechanical contraction of papillary muscle preparation related to calcium handling failure (7). Based on this, we investigated whether calcium cycling dysfunction in the myocardium of young rats submitted to severe food restriction is associated with altered SERCA2, PLB and RYR2 mRNA expression.

The present study provides important information about a significant decrease of myocardial RYR2 mRNA expression accompanied by no alterations in PLB or SERCA2 mRNA expression. These results suggest that food restriction differently affects the modulation of sarcoplasmic reticulum genes involved in calcium handling, and the experimental food restriction protocol caused only changes in RYR2 mRNA expression.

To the best of our knowledge, few studies have investigated the participation of myocardial $\mathrm{Ca}^{2+}$ cycling during malnutrition in rodents. Other investigations have also observed alterations in $\mathrm{Ca}^{2+}$ cycling induced by food restriction. O'Brien et al. (8) showed depressed $\mathrm{Ca}^{2+}$-ATPase pump and ryanodine channel activities in rats fed a low-protein-calorie diet. Rupp et al. (9) showed that myocardium of rats submitted to food restriction have reduced SR $\mathrm{Ca}^{2+}$ uptake activity. The differences in results between the studies by O'Brien et al. (8) and Rupp et al. (9), and our data on SERCA2 may be due to different food restriction protocols and different SERCA2 analysis methods.

The down-regulation of RyR2 mRNA gene expression induced by food restriction observed in the present study is also ob- served in other situations such as cardiac hypertrophy, diabetes mellitus and heart failure (15-17).

The mechanisms behind this change in myocardial RYR2 mRNA expression under food restriction are unknown. Although there are a variety of cell mediators that modulate RYR2 activity in the heart, including physiological modulators (e.g., ATP, $\mathrm{Ca}^{2+}$, and $\mathrm{Mg}^{2+}$ ), the direct modification of RYR2 protein (e.g., phosphorylation, dephosphorylation, and oxidation), and pharmacological agents (e.g., ryanodine, caffeine, etc.) (1820 ), there is no information on the factors involved in the regulation of ryanodine gene transcription. It is therefore difficult to suggest a mechanism to account for the downregulation of ryanodine channel mRNA expression in the myocardium of food-restricted rats.

The present study shows down-regulation of the ryanodine channel with no changes in SERCA2 PLB mRNAs in the myocardium of rats submitted to severe food restriction. This suppression may underlie the molecular pathogenesis of cardiac dysfunction. Further studies on the molecular defects contributing to abnormal $\mathrm{Ca}^{2+}$ cycling in myocardial impairment during food restriction may lead to a refinement of our understanding of the relationship between this condition and calcium signaling pathways.

\section{Acknowledgments}

The authors thank José Carlos Georgette, Mario Bruno, and Sueli Clara for technical assistance.

\section{References}

1. Berner YN, Stern F. Energy restriction controls aging through neuroendocrine signal transduction. Ageing Res Rev 2004; 3: 189-198.

2. Keenan KP, Laroque P, Ballam GC, Soper KA, Dixit R, Mattson BA, et al. The effects of diet, ad libitum overfeeding, and moderate dietary restriction on the rodent bioassay: the uncontrolled variable in safety assessment. Toxicol Pathol 1996; 24: 757-768.
3. Ramsey JJ, Harper ME, Weindruch R. Restriction of energy intake, energy expenditure, and aging. Free Radic Biol Med 2000; 29: 946968.

4. Okoshi K, Fioretto JR, Okoshi MP, Cicogna AC, Aragon FF, Matsubara LS, et al. Food restriction induces in vivo ventricular dysfunction in spontaneously hypertensive rats without impairment 
of in vitro myocardial contractility. Braz J Med Biol Res 2004; 37 : 607-613.

5. Cicogna AC, Padovani CR, Okoshi K, Aragon FF, Okoshi MP. Myocardial function during chronic food restriction in isolated hypertrophied cardiac muscle. Am J Med Sci 2000; 320: 244-248.

6. Okoshi K, Matsubara LS, Okoshi MP, Cicogna AC, Fioretto JR, Padovani CR, et al. Food restriction-induced myocardial dysfunction demonstrated by the combination of in vivo and in vitro studies. Nutr Res 2002; 22: 1353-1364.

7. Sugizaki MM, Dal Pai-Silva M, Carvalho RF, Padovani CR, Bruno A, Nascimento AF, et al. Exercise training increases myocardial inotropic response in food restricted rats. Int J Cardiol 2006; 112: 191201.

8. O'Brien PJ, Shen H, Bissonette D, Jeejeebhoy KN. Effects of hypocaloric feeding and refeeding on myocardial $\mathrm{Ca}$ and ATP cycling in the rat. Mol Cell Biochem 1995; 142: 151-161.

9. Rupp H, Maisch B, Brilla CG. Schedule-induced psychological stress and molecular structures of cardiomyocytes. Am J Physiol 1997; 272: R776-R782.

10. Fabiato A. Calcium-induced release of calcium from the cardiac sarcoplasmic reticulum. Am J Physiol 1983; 245: C1-C14.

11. Benevenga NJ, Calvert C, Eckhert CD, Fahey GC, Greger JL, Keen $\mathrm{CL}$, et al. Nutrient requirements of the laboratory rat. In: Benevenga NJ, Calvert C, Eckhert CD, Fahey GC, Greger JL, Keen CL, et al. (Editors), Nutrient requirements of laboratory animals. 4th edn. Washington: ILAR; 1995. p 11-79.

12. Mirit E, Palmon A, Hasin Y, Horowitz M. Heat acclimation induces changes in cardiac mechanical performance: the role of thyroid hormone. Am J Physiol 1999; 276: R550-R558.
13. Coussin F, Macrez N, Morel JL, Mironneau J. Requirement of ryanodine receptor subtypes 1 and 2 for $\mathrm{Ca}(2+)$-induced $\mathrm{Ca}(2+)$ release in vascular myocytes. J Biol Chem 2000; 275: 9596-9603.

14. Alway SE, Degens H, Lowe DA, Krishnamurthy G. Increased myogenic repressor Id mRNA and protein levels in hindlimb muscles of aged rats. Am J Physiol Regul Integr Comp Physiol 2002; 282 : R411-R422.

15. Hittinger L, Ghaleh B, Chen J, Edwards JG, Kudej RK, Iwase M, et al. Reduced subendocardial ryanodine receptors and consequent effects on cardiac function in conscious dogs with left ventricular hypertrophy. Circ Res 1999; 84: 999-1006.

16. Yamamoto T, Yano M, Kohno M, Hisaoka T, Ono K, Tanigawa T, et al. Abnormal $\mathrm{Ca}^{2+}$ release from cardiac sarcoplasmic reticulum in tachycardia-induced heart failure. Cardiovasc Res 1999; 44: 146155.

17. Teshima Y, Takahashi N, Saikawa T, Hara M, Yasunaga S, Hidaka $\mathrm{S}$, et al. Diminished expression of sarcoplasmic reticulum $\mathrm{Ca}(2+)$ ATPase and ryanodine sensitive $\mathrm{Ca}(2+)$ channel mRNA in streptozotocin-induced diabetic rat heart. J Mol Cell Cardiol 2000; 32: 655664.

18. Vlasblom R, Muller A, Musters RJ, Zuidwijk MJ, Van Hardeveld C, Paulus WJ, et al. Contractile arrest reveals calcium-dependent stimulation of SERCA2a mRNA expression in cultured ventricular cardiomyocytes. Cardiovasc Res 2004; 63: 537-544.

19. Meissner $\mathrm{G}$. Molecular regulation of cardiac ryanodine receptor ion channel. Cell Calcium 2004; 35: 621-628.

20. Fill M, Copello JA. Ryanodine receptor calcium release channels. Physiol Rev 2002; 82: 893-922. 